\title{
cMR in acute myocardial infarction: correlation between myocardial scar and echocardiographic strain
}

\author{
Gaby Weissman ${ }^{*}$, Michael Kern², Ana Barac ${ }^{1}$, Manuel A Gonzalez', Rebecca Torguson', Ron Waksman', \\ Anthon Fuisz ${ }^{1}$
}

From 15th Annual SCMR Scientific Sessions

Orlando, FL, USA. 2-5 February 2012

\section{Summary}

Global longitudinal and circumferential strain was assessed by echo in 15 patients after acute MI. MRI parameters including ventricular volumes, scar, and area at risk were assessed $3+/-2$ days post STEMI and at 30 day follow up. Echo strain measures correlated most strongly with LVEF ( $r=0.81$ and 0.88 longitudinal ad circumferential strain, $\mathrm{p}<0.0001)$ and infarct size $(\mathrm{r}=-0.68$ and $\mathrm{r}=-0.69, \mathrm{p}<0.001)$. There were moderate correlations between longitudinal strain and change in LVEDV $(r=-$ $0.61, \mathrm{p}<0.05)$.

\section{Background}

Cardiac MR (CMR) is a powerful tool in the evaluation myocardial scar and volumes. Speckle tracking by echo is used to evaluate myocardial strain. The correlation between strain measures and MR measures of scar is not well defined.

\section{Hypothesis}

CMR parameters, area at risk (AAR), infarct size (IS), and salvage area (SA), correlate with global echo strain in patients with a ST elevation MI (STEMI).

\section{Methods}

Contrast enhanced(CE) CMR and 2-D echocardiography imaging were performed in patients within $3+/-2$ days post STEMI. CMR-derived IS was measured from the late $C E$ images and AAR was measured from T2 black blood images. SA was calculated as AAR/IS. Global longitudinal (LS) and circumferential (CS) strain were assessed from standard apical (16 segment model for LS) or midventricular short axis views using 2-D speckle-tracking software (2D CPA, TomTec, Germany).

\section{Results}

15 patients with STEMI completed the protocol. Age was $50.8+/-12.6$ years ( $86.7 \%$ male). Baseline LVEDV was $203.4+/-51.7 \mathrm{ml}$ and $\mathrm{EF}$ was $51.1 \%+/-14.7 \%$ with follow up LVEDV $219.9+/-72.2 \mathrm{ml}(\mathrm{p}=0.15)$ and EF $50.8 \%+/-13.8 \%(\mathrm{p}=0.8)$. Average IS was $16.4+/-10.4 \%$, AAR was $23.4+/-12.2 \%$, and SA was $7.0+/-5.7 \%$ at baseline. Baseline LS was $-13.5+/-4.1$ and CS was $-19.4+/$ 6.3. Global longitudinal strain was associated with peak troponin I levels $(\mathrm{r}=-0.74, \mathrm{P}<0.001)$. Correlating LS and CS to baseline MRI parameters showed a strong correlation to LVEF ( $\mathrm{r}=0.81$ and 0.88 respectively, $\mathrm{p}<0.0001)$ and IS $(r=-0.68$ and $r=-0.69, p<0.001)$. There was moderate correlation of LS and CS to LVEDV ( $r=-0.55$ and -0.57), $\mathrm{p}<0.05)$ and AAR $(\mathrm{r}=-0.61$ and $\mathrm{r}=-0.57, \mathrm{p}<0.05)$. There was no correlation between strain and SA. There were modest correlations between initial LS and change in LVEDV but not with CS and change in LVEDV $(r=-$ $0.61, \mathrm{p}<0.05$ and $\mathrm{r}=-0.48, \mathrm{p}=0.07)$.

\section{Conclusions}

Echo strain measurements correlated most strongly with LVEF and IS. There were modest associations between strain at baseline and early LV remodeling.

\section{Funding}

None.

'Washington Hospital Center, Washington, DC, USA

Full list of author information is available at the end of the article 


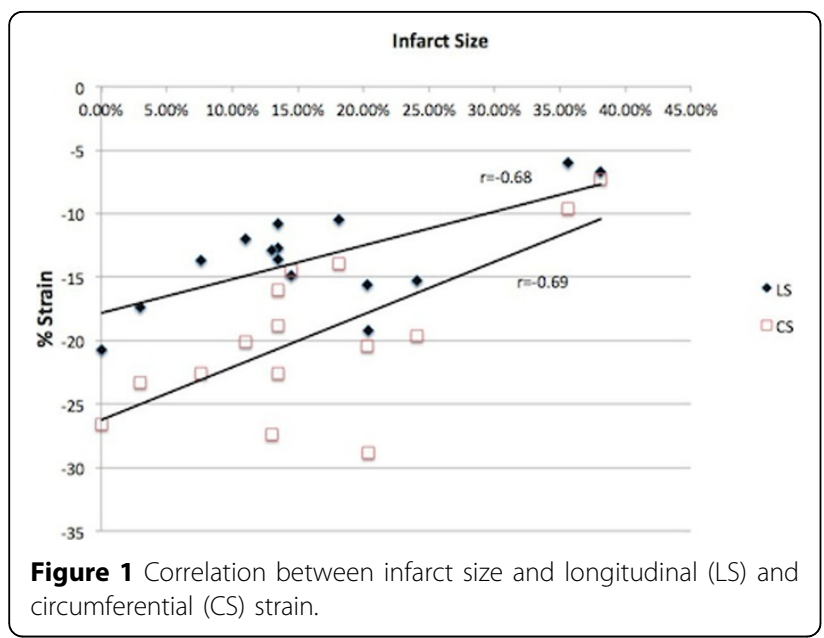

\section{Author details}

${ }^{1}$ Washington Hospital Center, Washington, DC, USA. ${ }^{2}$ Case Western Reserve University, Cleveland, OH, USA.

Published: 1 February 2012

doi:10.1186/1532-429X-14-S1-P25

Cite this article as: Weissman et al:: cMR in acute myocardial infarction: correlation between myocardial scar and echocardiographic strain.

Journal of Cardiovascular Magnetic Resonance 2012 14(Suppl 1):P25.

Submit your next manuscript to BioMed Central and take full advantage of:

- Convenient online submission

- Thorough peer review

- No space constraints or color figure charges

- Immediate publication on acceptance

- Inclusion in PubMed, CAS, Scopus and Google Scholar

- Research which is freely available for redistribution

Submit your manuscript at www.biomedcentral.com/submit 